\title{
La práctica judicial en las causas matrimoniales de la sociedad española del siglo XVIII
}

\author{
Margarita Ortega López *
}

\begin{abstract}
RESUMEN ABSTRACT
El trabajo muestra los

The study shows the behaviours and strategys, that follow the spanish courts during the XvII century in the matrimonial lawsuit. In them perceive it, haw they search for perpetuate insistencely the coexistence between the husbands, under the basic principle of the masculine authority and femenine obedience; existing a obvious accomplicity between the magistrate and the family's leader affected.
\end{abstract}

La importancia y supremacía de todo grupo, familiar o corporativo, sobre la persona, fue una característica significativa de la sociedad europea preindustrial, y todavía perceptible en la sociedad española del siglo xVIII. Por eso fue emergiendo, desde la época feudal, una organización del poder fragmentario, subsiguientemente acompañado por el surgimiento de numerosas jurisdicciones. Todavía continuaba ese básico estado de cosas en el sigio XVIII, aunque el esfuerzo y los resultados de ir incorporando poder a la monarquía absoluta fue — como es sabido- muy notable.

* Universidad Autónoma de Madrid 
De entre todas las numerosas corporaciones, la familia ocupó una prioridad significativa y toda la teoría política moderna la otorgó singularidad extraordinaria, pues se consideró a la sociedad civil, como un remedo y una prolongación de ella. J. Bodín, manifestaba en el siglo Xvı cómo: «la familia es la verdadera imagen de la República y el poder doméstico del padre de familia se parece al del soberano. El recto gobierno de la casa es el recto modelo del gobierno de la República" ".

Toda la literatura jurídica posterior, con la escolástica a la cabeza, coincidía en comparar al cabeza de familia con el soberano, en cuanto a la posesión de jurisdicción, uno ubicado en el ámbito de la casa y otro en el ámbito de la política. El varón, cabeza de familia, fue conferido de un «impérium" incontestable, poseyendo autoridad sobre el grupo formado por la esposa, hijos, familiares y criados o esclavos. El ideal del «pater familias» quedó conceptualizado, en un varón responsable inserto en una comunidad corporativa, donde desempeñaba su función profesional o social, que cumpliese con sus obligaciones religiosas, fiscales o militares y que preservara la honra de su linaje.

La esposa, según este modelo establecido, había de cumplir los principios patriarcales de obediencia al esposo, amor desinteresado al clan, laboriosidad doméstica probada y capacidad reproductiva para perpetuar el linaje. Evidentemente, en la pareja matrimonial existían unas relaciones de género, no igualitarias, encaminadas a manifestar la superioridad del varón sobre la mujer y asegurar la adecuada transmisión del apellido y de la propiedad a los hijos legítimos. La importancia de mantener el honor de la familia descansó fundamentalmente en preservar incólume la honestidad de sus mujeres. El contrato social que el matrimonio encubria descansaba previamente, como señala C. Paterman, "en el contrato sexual de propiedad masculina" ${ }^{2}$.

Proteger, alimentar y cuidar a la familia era una obligación ineludible para el varón como lo era para la esposa dar descendencia, obedecer al marido y ocuparse del gobierno doméstico. La reiteración machacona, tanto desde la literatura moral o política como desde la diversa publicística de la época, no puede hurtarnos de constatar que, aunque fue éste un modelo familiar de aceptación generalizada, no se desarrolló sin fisuras.

1 Bodin, J., Los seis libros de la república, Ed. P. Bravo. Madrid, 1985. Clavero, B. Antidora: antropología católica de la economía moderna. Milán, 1991. Frigo-Mozzareli (Eds)., Goberno della casa, goberno della citá. Cheirou, 1985. HESPANHA, A., Pcoder e instituciones en la Europa del antiguo régimen. Madrid, 1993.

2 Paterman, C., El contrato sexual. Madrid, 1997. Fraiser, G., La musa de la razón, la democracia excluyente y la diferencia de sexos. Madrid, 1992. MOLINA, C., Dialéctica feminista de la ihustración. Madrid, 1994. 
Las fuentes contenciosas españolas del siglo XVIII nos proporcionan abundantes muestras de cómo esos planteamientos estereotipados no siempre se plasmaban en realidades. No es posible mantener, sin matices, el "idearium» de mujer obediente, pasiva y cómplice de su propia victimización. Lo que no quiere decir que no existieran muchas mujeres así, incapaces de trascender otros horizontes. Tampoco es defendible, sin matices, la imagen de un cabeza de familia autoritario y distante, que suelen desprender numerosos textos. Existieron hombres afectuosos que vivieron en armonía con su familia y especialmente desde que, en el siglo $X V I I I$, la divulgación de la literatura sentimental pusiese énfasis en impulsar la corrección del mundo de la sensibilidad y los sentimientos para ambos sexos. Juan Hernández, por ejemplo, peletero zaragozano, en 1753, decía: "haber sido feliz llevando una vida adecuada con Isabel Modrego, su esposa y sus cuatro hijos...., a pesar de las difíciles situaciones en las que la vida le había colocado" ${ }^{3}$. Y en escritos de ilustrados significativos, como Jovellanos, el cuidado de la sensibilidad se consideró determinante en la educación de las élites, tanto en los hombres como en las mujeres.

El propósito de este trabajo es analizar los comportamientos judiciales y sus estrategias de resolución de los conflictos existentes en las parejas matrimoniales, así como las actitudes que mostraron para su defensa. No obstante la documentación contenciosa -en la que me baso-, no puede hacernos ignorar las dosis de felicidad conyugal lograda por determinadas parejas que solucionaron conjuntamente, y sin mediación exterior, sus pareceres encontrados. No es mi intención desvalorizar las plurales y complejas relaciones familiares en el marco de una sociedad preindustrial; más bien al contrario, persigo delimitar cuáles eran las posibilidades teóricas de solución que daba la monarquía hispana a aquellas parejas incapacitadas para llevar una existencia armónica.

Los distintos sistemas judiciales -fuesen civiles o eclesiásticos, realengos o señoriales-, compartían la superioridad de la cultura jurídica patriarcal vigente y mostraban su capacidad a través de medios informales o institucionales para apaciguar, encauzar o castigar a las partes en conflictos. Indudablemente cuando hacian esto, eran conscientes de introducirse en un terreno vidrioso y difícil, habitualmente bajo el «imperium» del esposo, pero que ellos transitoriamente ejercian por la existencia grave de un conflicto entre las partes. El propio derecho otorgaba toda la autori-

A.H.N. Consejos, libros 1371 , folio 189 , año 1753. Un pleito contra el gremio al que pertenecía, lo elevó al Consejo de Castilla en grado de apelación. 
dad sobre la esposa al "pater familias». La Instrucción de Corregidores de 1788 era bien explícita al respecto:

"se abstendrán los corregidores de tomar conocimiento de oficio, en asuntos privados de padres a hijos, maridos a mujeres, amos a criados, cuando no haya queja grave ni escándalo para no perturbar el interior de las familias; antes bien ellos han de contribuir a su quietud y sosiego' ${ }^{4}$.

Resulta esclarecedora la filosofía que desprende la Instrucción, y que estaba en la mentalidad colectiva española; el grupo familiar era un dominio privativo del cabeza de familia y sólo cuando no podía controlarlo por si mismo, la jurisdicción judicial lo sustituía conyunturalmente hasta restablecer de nuevo su potestad.

En el momento que se reconducian las situaciones que habian creado un escándalo social, y que por eso salían de la jurisdicción privada del «pater familias", se restablecía el orden patriarcal establecido. Su poder era, en sí mismo, transitorio, y tenía siempre la finalidad de hacer posible una convivencia aceptable entre hombre y mujer; es decir una relación de autoridad y superioridad de él sobre ella, a la que siempre el derecho consideraba dependiente ${ }^{4 a}$.

En la mayoría de las situaciones, su base argumental fue hacer ver a las partes sus errores y ayudarles a solucionar sus problemas. Cuando éstos habian desaparecido, la función arbitral de los jueces, alcaldes o corregidores, se diluía. Incluso su actitud era similar cuando era posible realizar acciones de concordia o fórmulas diversas de disuasión. Por esa causa, antes de acudir a la justicia ordinaria se agotaba todo tipo de acciones pactistas que ayudaran a resolver los conflictos, y sólo cuando ello no era posible, comenzaba de oficio la trayectoria habitual en la resolución de los contenciosos.

Me ha interesado analiza: diversos tipos de materiales documentales con la idea de delimitar a través de qué procedimientos posibles, y constatables, se encauzaban las tensiones de género en la sociedad española del siglo XVIII. Concordias ante notario, pactos ante el alcalde -ordinario o mayor si era territorio de señorío-, o ante alcaldes y corregidores o ante las audiencias o las chancillerías o incluso ante el Consejo de Castilla, como máximo órgano de resolución de los conflictos de la Monarquía hispana. Esos han sido algunos de los fundamentos de esta investigación.

4 Instrucción de Corregidores en 1788, A.H.N. Consejos, leg. 1526, exp. 34. Sobre la autoridad marital ver MUÑoz, M.J., Las limitaciones de la capacidad de obrar de la mujer casada, 1505-1975. Madrid, 1995. VVAA., Ordenamiento juridico y realidad social de las mujeres. Madrid, UAM, 1994

4a Ortega, M., Las mujeres de Madrid como agentes de cambio social, (Ed.) Madrid, 1995. 
Y a través de ellos, se observa que, a pesar de que no variaron las relaciones de poder existentes, implantadas por el sistema patriarcal, algunas mujeres esbozaron mecanismos y formas de comportamiento que denotaban y demostraban las fisuras y abusos de ese modelo patriarcal vigente.

La voluminosa documentación contenciosa desarrollada en la sociedad española del siglo xVIII es muy conocida. Menos conocida, pero real, son las abundantes causas judiciales ${ }^{5}$ que, en materia familiar, custodian nuestros archivos. Destaca, en primer lugar, la insistencia con que las mujeres acudian a los tribunales para solucionar situaciones de abusos o de desprotección masculina. Pero ciertamente las mujeres, como los hombres, recuperaron con la nueva dinastía la esperanza de acceder a tribunales operativos e independientes que hicieran cumplir las leyes que esa sociedad se había dado a sí misma.

En esos comportamientos es necesario valorar la impronta que la revolución intelectual y científica acarreó en toda Europa, impulsando un deseo general de regeneracionismo y de felicidad a la vez que trascendía el miedo y pesimismo que la sociedad de la Contrarreforma ayudó a propagar $^{6}$. Esa visión, más optimista de la naturaleza humana, fue poniendo en tela de juicio principios inalterables anteriores que, como la necesaria obediencia al superior, fue perdiendo importancia al extenderse la costumbre entre la sociedad más formada de enjuiciar las cosas con independencia, es decir, comprobar la legitimidad y la utilidad de cualquier autoridad.

Es significativa la relativa prontitud con la que Alcaldes y Magistrados intentaron mediar en los conflictos matrimoniales. Evidentemente, seguían estando vigentes los principios políticos que identificaban a la familia como base de la sociedad civil, y por tanto su salvaguarda se concebía como una categoría de la máxima importancia. Se perseguía la armonía dentro de la casa y se impedian algaradas, escándalos y alteraciones del orden público, y nada fue más querido a la monarquía borbónica que mantener esos principios, especialmente a partir de los motines de 1766. Se mostraba en toda su coherencia la lógica del sistema del Antiguo Régimen,

\footnotetext{
5 Demerson, J.P., Sexo, amor y matrimonio en Ibiza. Palma de Mallorca, 1993. Pascual, M.J. "Mujeres y conflictos familiares, demandas de justicias y estrategias discursivas en el mundo hispano del setecientos", en Mujeres, regulación de conflictos y cultura de la paz. Valencia, 1999. ORTEGA, M., "Relaciones de género y familia en el sigio XVIII: teoría y práctica", en El conde de Aranda y su tiempo. Zaragoza, 1999; "Protestas de mujeres castellanas contra el orden patriarcal privado durante el siglo xvIII», Revista de Historia Moderna. Universidad Complutense, 1996.

- ORtEga, M., "Algunos cambios de las mujeres madrileñas en el siglo Xvili", en Las mujeres y la ilustración, Universidad de Cádiz, 1994. SAnChEz Blanco, M., La cultura ilustrada. Madrid, 1999. Elias, N., El proceso de civilización. Madrid, 1987.
} 
cuando el cabeza de familia se veía incapacitado para ejercer su poder sobre el grupo familiar. Entonces, como sucedía en otras instituciones, se suspendia provisionalmente el poder autoregulador de los distintos cuerpos existentes en esa sociedad corporativa ${ }^{7}$ Por esa causa, los jueces y los alcaldes, se hacian cargo de esos conflictos matrimoniales que no eran capaces de solucionarse dentro del ámbito del hogar. De este modo se era coherente con los principios jurídicos que la comunidad y la sociedad se había otorgado a si misma.

\section{ASUNTOS CONFLICTIVOS}

El discurso oficial sobre el matrimonio postridentino, hizo hincapié en su carácter contractual -más teórico que real si nos atenemos a su funcionamiento-, que mostraba la obligación del esposo a la protección de la familia, a cambio de la obediencia de aquélla en todo lo que fuese racional y justo ${ }^{8}$.

Fue difícil delimitar qué se entendía realmente por tales conceptos, pero el carácter jurídico no arbitrario de la autoridad masculina permitió algún cuestionamiento a esa autoridad patriarcal por parte de la esposa o de la parte afectada.

La interpretación personal que algunas esposas pudieron hacer a esa consideración sobre las relaciones matrimoniales entre hombres y mujeres, las llevaron a presentar esas tensiones en el ámbito público. Con frecuencia cada cónyuge pudo tener apreciaciones diferentes sobre el desempeño de sus funciones y ésas se expusieron ante los encargados por parte del Rey de impartir justicia.

En general los conflictos se originaron por razones de desamor, desprotección o malos tratos; pero especialmente me interesa analizar aquellas disensiones surgidas del ejercicio de la autoridad masculina, bien por exceso o por defecto. Es decir, tanto los problemas generados por abusos de poder por parte del esposo sobre la mujer, como la excesiva benevolencia o blandura de aquél para ejercer su autoridad sobre ella. Del mismo modo que existieron numerosos maridos dominantes, algunas esposas conseguieron imponer sus deseos invirtiendo el orden patriarcal en las relaciones

\footnotetext{
7 Hespanha, A., La gracia del derecho, Madrid, 1993. Clavero, B., El código y el fuero, Madrid, 1983.

\& Donoso, J., Instituciones de derecho canónico, Valparaiso, 1849. Muñoz, J., El derecho de la mujer casada..
} 
de pareja. Ese hecho fue tomado en consideración como algo extraordinariamente subversivo para la convivencia matrimonial. $Y$ aunque innegablemente el primero de los casos fue el mayoritario, las fuentes nos muestran cómo también existieron mujeres que se hicieron con el «imperium» en el ámbito familiar y así lo denunciaba el varón, apoyado casi siempre por grupos externos a la propia familia. Incluso cuando un cabeza de familia mostraba su incapacidad para hacer valer su «imperium» sobre la misma, enseguida la comunidad a la que pertenecía - vecinos, familiares, corporaciones....-, se sentía en la obligación de denunciar esos subversivos hechos ante la magistratura correspondiente.

En 1747, Micaela Orozco, esposa de un cabeza de familia de Cartagena de 40 años, y que ella misma se autodefinía como "una pobre señora de distinguido nacimiento", denunciaba el poder despótico y los malos tratos que ejercía su marido sobre ella y sobre sus dos hijos, por lo que acudió a la Magistratura para su defensa ${ }^{9}$. Como ella, otras mujeres solicitaron el poder mediador de las autoridades municipales o de los representantes de la justicia para solventar conflictos domésticos o matrimoniales ${ }^{10}$ de difícil solución dentro del ámbito del propio hogar. Pero en este trabajo fundamentalmente me interesa analizar cómo la desobediencia femenina a las disposiciones maritales generó tensiones y conflictos.

Mucho más extraño fue el fenómeno contrario de esposas que avasallaban las decisiones maritales aunque igualmente real. Carmen Martínez, esposa del alcalde de Villatobas, Toledo, ridiculizaba y menospreciaba a su esposo, agricultor de profesión, a la vez que era la única administradora de la hacienda familiar entre el escándalo y el ridículo que el marido hacía ante el vecindario ${ }^{11}$. Allí un grupo de vecinos ayudó al esposo a acudir a la justicia, denunciando tanto su inadecuada introducción en los asuntos concejiles, de única incumbencia del marido, como la desobediencia contumaz a su autoridad. Quizás, ésa fue la causa por la que 15 vecinos del pueblo declararon la inapropiada conducta de esposa, a la vez que explicaban el ridículo con el que el alcalde se mostraba a los ojos del vecindario.

Del mismo modo Josefa Royo, mujer de un oidor de la audiencia de Valencia, fue denunciada al Consejo de Castilla por un grupo de personas

9 A.H.N. Estado, leg. 4828, año 1747. El padre, la pegaba e impedía a su hija de 11 años entrar en un convento de capuchinas.

10 Ortega, M., "Protesta de mujeres...".

A.H.M. Consejos. Libro 1371, año 1783. Denunciaban 4 testigos, numerosos actos de prevaricación y de abuso de poder de la esposa. 
anónimas, estando pendientes sus conflictos de resolución del juzgado sobre su esposo, a quien tenia dominado e incapacitado - al parecerpara ejercer adecuadamente con sus obligaciones jurisdiccionales. El carácter anónimo de este documento ${ }^{12}$, donde se reflexiona sobre lo subversivo e inadecuado que era que una mujer ejerciese el poder marital, hizo posible una inspección en la que, en efecto, se constató la dejadez del esposo y el excesivo poder que ella ejercía sobre las resoluciones y dictámenes de su juzgado. ¿Quizás fue un anónimo inducido a instancia del propio juez, incapaz de armonizar su vida familiar y profesional? No es posible saberlo, pero aunque, como consecuencia de esa denuncia, se le depuso de su cargo de la audiencia de Valencia, siendo enviado a una plaza de menor importancia, se exigió y conminó a la esposa a la obediencia y respeto a las consideraciones del cabeza de familia. Se restituían así unas relaciones de poder patriarcales que nunca debían haberse modificado.

También es necesario observar, en este esbozo de tipologías posibles en relación a la dependencia femenina del cabeza de familia, los intentos fallidos de algunos esposos por recuperar la autoridad que poseían sobre su casa y que, en la mayoría de los casos, se tradujo en violencia y escándalos en el hogar, cuando no en situaciones que alentaban a la sanción o a la comicidad del entorno vecinal.

Eugenia Álvarez, esposa de un labrador de Tierra de Campos, Palencia, en 1768 , era una asidua reclamante ante la alcaldía del pueblo contra su marido al que acusaba de malos tratos ${ }^{13}$. En el pleito criminal incoado ante la Chancilleria de Valladolid por la continua repetición de escándalos e injurias mutuas, los testigos explicaron las continuas algaradas y gritos de la pareja y su imposibilidad de convivencia. Aquí se solicitó la intervención de la justicia tras muchos años de crisis, originada, a su parecer, por el excesivo carácter impetuoso de Eugenia y la bravuconería del esposo que no estaba capacitado para ejercer el «imperium» sobre la esposa.

Pero también la documentación presenta situaciones donde la esposa o el esposo abandonan el hogar tras años de tensiones, intentando una nueva vida extramatrimonial. En el caso masculino, las fugas y causas por bigamia tienen constancia documental, ayudándose frecuentemente para lograrlo de un cambio de identidad o de una nueva residencia.

i2 A.H.N. Estado. 4828. Causa reservada. Se detallaban numerosas prácticas delictivas que llevaba adelante Josefa con el consentimiento del marido. El anónimo no llevaba fecha ni año, pero solicitaban una inspección detallada del funcionamiento del juzgado denunciado de la audiencia de Valencia.

13 A.Ch. V. Pleitos criminales, caja 76-1. Llevaban 7 años con continuos problemas, año 1768. 
Una esposa de Murcia llevaba ocho años denunciando la fuga de su marido, militar de profesión, al que no se le encontraba a pesar de las descripciones pormenorizadas dadas a todos los corregidores españoles ${ }^{14}$. La esposa, aunque explicaba su situación de desamparo y la de sus 4 hijos, no se privó de señalar que era un "hombre malhumorado, de difícil contento", a pesar de lo cual ella siempre había respetado su autoridad. Esta mujer conocía bien la filosofía del poder conyugal y mostraba su aceptación a ella para su mejor defensa.

Pero también existíeron mujeres casadas que desaparecieron de su casa, en busca de una nueva vida. Bernarda Bravo ${ }^{15}$, esposa de un tendero de Segovia, desapareció del hogar conyugal en 1799, según el testimonio que su marido había presentado ante la justicia del pueblo. No pudo tampoco ser encontrada, a pesar de la colaboración de todos los corregidores del reino. De la testificación de varios vecinos en la causa, se adivinaba el descontento de la mujer ante el carácter avaro, autoritario y desconfiado que tenía el esposo.

\section{ESTRATEGIAS Y COMPORTAMIENTOS JUDICIALES}

\subsection{La Mediación}

Los distintos tribunales de justicia españoles se mostraron fundamentalmente mediadores en los conflictos familiares. En realidad, operaron con frecuencia como agentes pactistas, protectores de la estabilidad familiar más que como impartidores de justicia. La singularidad de estas materias contenciosas, y los principios constitutivos que regían la lógica judicial en estas cuestiones de índole privado, así lo recomendaba. Hasta tal extremo se desarrollaron los trabajos de mediación de las autoridades judiciales que no es inverosímil pensar que muchas de las causas incoadas no tuviesen otra finalidad que presionar o dar un aviso a la parte contraria sobre la improcedencia de determinadas conductas. $Y$ esas situaciones, fueron comunes tanto en las querellas presentadas por los maridos como por las mujeres.

Esa idea parece que es la que subyace en las numerosas causas judiciales que se interrumpen nada más ser comenzadas, y de las que poco $o$

\footnotetext{
14 A. H.N. Estado, leg. 4828, 177/A. De sus testificaciones se deducían muchos conflictos entre la pareja, aunque ellla manifestaba su cariño y su desconsuelo por esa situación.

15 A. Ch. V. Pleitos Criminales, Caja, 250-7. Se decia que la mujer se podia alimentar a duras penas, con la ayuda de familiares y vecinos.
} 
nada se puede conocer. Procedimiento éste, por lo demás, que era afín también a otras materias problemáticas en donde la fórmula de apercibimiento a las partes fue muy utilizada. Por ejemplo, un capitán de caballería de Barcelona denunció por adulterio a su esposa, que había huido a $\mathrm{La}$ Coruña como amante del capitán general de Galicia en $1774^{16}$. El marido señalaba en su denuncia la dificultad que había tenido siempre para ejercer su autoridad como cabeza de familia.

La justicia de Cataluña y Galicia se coordinaron para deponer ese escándalo. Se censuró al Marqués de Caylús, capitán general de Galicia, y se le recriminó a la esposa del artillero su mala conducta, a la par que se le facilitaba el perdón del marido ultrajado. La causa judicial ni siquiera llegó a plantearse.

Del mismo modo, la esposa de un jornalero de Chinchón ${ }^{17}$ denunció el amancebamiento de su esposo Ramón García, "Ramoncillo" en el texto, con una mujer de La Granja de San Ildefonso; y daba datos precisos para su identificación a la vez que mostraba la indefensión en la que se encontraba su familia. La justicia de La Granja de San Ildefonso, apresó fácilmente a García y le conminó a volver al hogar y a desarrollar una vida adecuada con su esposa y su familia. García volvió a convivir con su esposa en Chinchón ya que la solución, pactada a instancia de la Magistratura, resultó posiblemente eficaz ante el conocimiento de la pena que acarreaba el amancebamiento. En efecto, desde Felipe II esas situaciones se penaban con vergüenza pública y 10 años de galeras ${ }^{17 a}$ y Ramón García no deseaba terminar su vida de forma tan terrible.

Estas acciones fueron comunes a los distintos tribunales encargados de solucionar causas matrimoniales. En efecto, con esos conflictos hubieron de toparse tanto los tribunales señoriales como los de los territorios realengos - fuesen corregimientos, audiencias o chancillerías-.

Las denuncias de conflictos matrimoniales no sólo podían ser elevadas por los propios interesados sino que, a menudo, los problemas de las familias tenian un carácter supraindividual, en la que una parte o toda la comunidad - sobre todo en pueblos pequeños-, se sentía implicada en los litigios de algunos de sus componentes; bien porque generaban escándalo

\footnotetext{
16 A. H. N. Estado, leg. 4828. El escándalo en La Coruña era notable pues el capitán general, marqués de Caylús, era a la vez el presidente de la audiencia.

17 A.H.N. Consejos, Libro 1365, año 1770. La esposa hablaba en términos despectivos de la amante de su marido.

i7a Novisima recopilación de leyes de Indias. Libro VIII, título 20, ley 8 . Felipe II endureció todavía más esos delitos que, en la época de Carlos I ya se había modificado con la pena en galeras.
} 
público, bien porque dañaban la reputación de una casa o bien porque había que poner coto a determinada violencia familiar.

Ya se ha señalado anteriormente la prontitud con la que algunos vecinos acusaron a algún cabeza de familia ejerciente de jurisdicción de determinadas manipulaciones que efectuaban sus esposas sobre ellos. Pero mucho más frecuentes fueron las denuncias de las esposas de vecinos o familiares 0 incluso del propio alcalde ordinario del concejo sobre la improcedencia de determinada conducta matrimonial. A. Hespanha ha explicado cómo en el orden jurídico del Antiguo Régimen, respondian fundamentalmente al producto de una tradición social, casi sagrada, donde no podían quebrarse las reglas fundamentales que esa sociedad se habia dado así misma ${ }^{18}$. Incluso en asuntos de índole privada, la impronta colectivista del sistema corporativo antiguorregimental mostraba el despliegue de su solidaridad. Así cualquier conflicto en torno a derecho, rebasaba el marco teórico-técnico en el que se insertaba e interpelaba a toda la comunidad implicada. En esas colectividades, el respeto a la moral y a las costumbres eran un asunto prioritario.

Evidentemente era fundamental proteger los intereses de los más débiles, sobre todo aquéllos que, no tenían un acceso fácil y directo a la justicia. En todo caso, con o sin apoyo de la comunidad, numerosas mujeres acudieron a los tribunales para solucionar o denunciar sus conflictos matrimoniales; y se encaminaron tanto a tribunales de orden civil como a los religiosos.

Por lo general, si la esposa agredida tenía padre, solía recurrir a él para que apoyara o presentara en su nombre la denuncia. Francisca Aguiara ${ }^{19}$, esposa vallisoletana de un tejedor, presentó con el aval de su padre, causa criminal ante la chancillería de Valladolid sobre el trato injurioso que le procesaba el marido. Era evidente que la actitud del esposo dañaba la credibilidad de la familia Aguiara y además la veracidad de su testimonio quedaba mucho mejor avalada con la constatación paterna.

Esos comportamientos de hijas casadas, a las que el padre apoyaba en su demanda, fueron abundantes y seguian plenamente la lógica patriarcal al ser avaladas las mujeres por el cabeza de familia correspondiente. En otros casos, si el padre de la demandante no vivía, el hermano mayor o algún varón de la familia solía reemplazar la función protectora y demandadora de justicia del padre de mujer ultrajada.

18 Hespanha, A., La gracia del derecho, Madrid, 1995

19 A. CH. V: Causa secretas, leg. 7. Exp. 13. año 1756. 
Pero las mujeres agredidas, aunque no tuvieran apoyos familiares, no fueron insensibles a buscar ayuda en la justicia cuando el cabeza de familia contravenía o abusaba de los principios jurídicos vigentes. Francisca Gurrea, vecina de Las Celadas, Burgos, acudió al alcalde de su pueblo para que la defendiese de las injurias vertidas por su marido. Francisca manifestaba como aquél divulgaba su deshonor por el vecindario sólo porque ella le recriminaba su excesiva dependencia del vino y su desatención por la alimentación de la familia. En esta grave situación, ella, como tantas otras mujeres, no tuvo reparo en acudir a la magistratura local ${ }^{19 a}$. En su lógica, el alcalde ocupaba el lugar y la protección que, en su caso, el marido no ejercía. Y obviamente la justicia fue especialmente sensible a la hora de solucionar, preservar o castigar el honor de esas personas; poseer la mujer una fama de honesta y virtuosa era indispensable en esa sociedad. En este caso, la llamada de atención de la autoridad judicial del pueblo, bastó para que el esposo volviese a la convivencia familiar adecuada.

La comunidad no solia hacer oídos sordos a situaciones claramente abusivas por parte del poder marital. Vecinos del barrio de la Corredera de Toro, Zamora ${ }^{20}$, enviaron una carta dirigida al fiscal de la Chancillería de Valladolid en 1800 , sobre el comportamiento abusivo de un regidor toresano, Antonio Melero, con su esposa, a la par que presentaban denuncia por la vida deshonrosa y escandalosa del propio Antonio Melero.

En la carta se deduce la ineficacia de anteriores gestiones vecinales para que el regidor depusiese la violencia que desarrollaba con la esposa, así como su vida licenciosa. Los vecinos alababan, en cambio, la buena conducta y la prudencia de la esposa y censuraban el mal comportamiento del regidor; obviamente el presumible corporativismo instalado en el ayuntamiento toresano, fue la causa de que, no confiando en su recto proceder institucional, elevaran su protesta al fiscal de la sala de lo criminal de la Chancillería de Valladolid.

Este caso, como en otros en los que estaban implicados personas de las clases privilegiadas o que ejercian funciones públicas, se introdujo en el silencio procedimental de Causas Reservadas de la Chancillería de Valladolid. Así se protegía la sociedad estamental del antiguo régimen de divulgar hechos improcedentes de sus estamentos privilegiados a la opinión pública. La abundancia y riqueza de sus expedientes avala la no inexistencia

19a Ortega, M., «Estrategias de defensa de las mujeres de la sociedad popular española del siglo xv!ll", Revista Arenal, n. ${ }^{\circ} 5$, julio-dic. 1998.

20 A. CH. V. Causas secretas, leg. 49. Exp. 3. Denunciaban la ineficacia de sus peticiones de honradez y al propio tiempo la incapacidad del ayuntamiento para corregir esas actuaciones 
de tensiones entre los muchos de las clases superiores de la sociedad española del Antiguo Régimen.

En los procedimientos sancionatorios, la justicia no sólo era dependiente de una demanda individual o colectiva; aunque, en la mayoría de los casos, se solía esperar a que alguien presentase cualquier demanda. Las causas de oficio abiertas por la justicia local, señorial o realenga, abundan en el material contencioso consultado; y especialmente en asuntos graves que vulneraban los principios penales, aunque en determinadas cuestiones, como los delitos contrarios al honor de las personas, la justicia no podía proceder de oficio sino a través de quejas esbozadas por algunas de las partes implicadas ${ }^{21}$.

Por ejemplo, el alcalde de San Vicente de la Barquera, Cantabria ${ }^{22}$, abrió causa de oficio contra Catalina Covalete, vecina y esposa de un ganadero de la comunidad por delito de infanticidio en 1776 . El nacimiento de un niño y su muerte prematura, a los dos días, indujo al alcalde a abrir expediente contra ella y contra dos vecinas que le habian ayudado en el hecho. Aunque el juez abrió causa por infanticidio, pronto se observó la raiz del problema que no era otro que una relación de adulterio, con el consiguiente embarazo. Posteriormente el marido corroboró las sospechas de la autoridad municipal, aunque dijo que no había acudido a demandarla para no poner en entredicho su honra. En la mayoría de los casos, el infanticidio solía ser fruto de la pobreza o de determinadas relaciones extramatrimoniales que se deseaba ocultar. Obviamente, la justicia había de perseguir los delitos que iban en contra de los principios sobre los que esa sociedad de asentaba, y solió ser consecuente en su defensa.

De oficio también, fue la causa abierta por la justicia de La Bañeza, León, por la violencia y malos tratos que un padre de familia daba a su esposa y a sus tres hijos en $1776^{23}$. El estado de desprotección, abandono y violencia en la que se encontraba la familia — con la madre enferma - fue el desencadenante de tal acción. La inasunción de responsabilidades por parte del cabeza de familia, supuso su condena a galeras por ocho años. Se hace necesario destacar, con claridad, la importancia que concedía la justicia y la sociedad para que se asumiesen siempre los deberes asignados al cabeza de familia con hijos a su cargo; así era necesario mostrar el castigo aplicado sin misericordia, para los que lo infringiesen en asuntos tan graves.

Novisima recopilación..., Libro VIII, 11, 4.

22 A. CH. V. Causas secretas, leg. 16, exp. 9, año 1776. El marido alegaba al comienzo desconocer el hecho; era al parecer fruto de una relación extramatrimonial.

23 A. CH. V. Pleitos Criminales, leg. 275-7. año 1776. 


\subsection{Procedimientos y sanciones}

Como se ha dicho la justicia señorial o realenga, instó y vigiló por el cumplimiento estricto del sistema patriarcal existente en las relaciones matrimoniales. Ciertamente son mucho más abundantes las acciones efectuadas ante los tribunales reales - que conocemos mejor-, pero incluso la justicia señorial no fue ajena a desarrollar este tipo de acciones.

Concepción Lacasa, esposa de un labrador-arrendatario de Pedrola, Zaragoza, y tendera ella misma de la tienda del señor, acudió en 1769 al alcalde del pueblo alegando desprotección del "pater familias" ${ }^{24}$. La falta de dinero para realizar la manutención que necesitaba la familia fue la razón que la llevó a solicitar la intervención judicial.

No hubo necesidad de acudir al alcalde mayor de la baronía de Luna, a la que pertenecía el lugar, pues la llamada de atención del alcalde ordinario de la villa al esposo parece que recondujo el problema. El expediente incoado contra ese labrador termina aquí. Pero no se terminó, en cambio, la causa presentada por una mujer soltera ante otro alcalde ordinario de señorío de la misma baronía. En efecto, Marta Ariza, vecina de Torres de Berrellén, Zaragoza ${ }^{25}$, no pareció contentarse con la labor efectuada por el alcalde del pueblo para acallar los rumores de vida deshonesta que se le imputaba. El alcalde se limitó aquí a amonestar a los y las difamadoras de la mujer agredida, y a pedir informes a tres vecinos sobre su conducta. En esos testimonios, los testigos coincidieron en la honorabilidad y honestidad de Marta, virtudes todas ellas centrales al «idearium" de la sociedad patriarcal que repetian incansablemente los moralistas y toda la literatura de la época.

Sin embargo, Marta apeló al alcalde mayor de señorío, pidiendo rectificación pública, amonestación y sanciones penales para los causantes de su injuria, entre los que estaba una vecina celosa de la cordialidad con la que su marido se dirigía a ella y que parecía ser la inductora del rumor.

Un año más tarde logró Ariza que sus difamadores se retractasen; pero las duras penas que ella perseguía no logró que se les imputaran porque, según la filosofía moral vigente, no era tan importante la demanda de cualquier mujer soltera y sola en demanda de honra, pues no ponia en entre-

24 Archivo Ducal Villahermosa (A.D.V.) Fondos Luna, leg. 18, exp. 32, año 1769. Se decía que el marido gastaba todo el dinero en la taberna.

A. D. V. Fondos Luna, leg, 23, exp. 53 y 54. 
dicho el buen nombre de una familia; sólo se perseguian duramente esos casos si la mujer era casada ${ }^{26}$.

Es fácil deducir cómo la ley no protegía tanto la honra de las mujeres como la de sus respectivos esposos, facilitando de ese modo la paz comunitaria. Al parecer el honor de la mujer soltera - mucho más si estaba sola - al no acarrear deshonra a un determinado hombre, no generaba tanto conflicto para la comunidad. Pura lógica juridica fundamentada en la falta de equidad que la razón patriarcal establecía en las relaciones de los sexos a la par que mostraba la desvalorizacion que la sociedad preindustrial concedía a cualquier mujer soltera, elemento pasivo en la función reproductiva de la sociedad.

Incluso en épocas tan avanzadas como la del siglo XVIII, es posible rastrear en los archivos señoriales determinados actos de concordia protagonizados por los señores, como representantes último de jurisdicción y que, a instancia de algunas de las partes, facilitaron pactos matrimoniales entre sus propios vasallos.

Quizás la cercanía y la solidaridad existente entre un escribano del señorío de Luna en Erla, Huesca, y su señor, fue el hecho que posibilitó la mediación del Conde en el matrimonio de aquél, en $1770^{27}$. Situaciones afines existieron en otros lugares señoriales españoles y europeos, poniendo de manifiesto cómo una más de las facetas del señor era otorgar mercedes a los que habían hecho algún mérito $o$ ayudar y proteger a solucionar y dilucidar conflictos que - como en este caso-, podían amenazar la estabilidad de una familia.

En menor medida que en los territorios realengos, también existieron peticiones directas al titular del señorío de esposas maltratadas o vejadas que solicitaban su mediación o su ayuda. En esos casos se dirigian al señor -como padre de familia-, encargado de velar por la estabilidad de todas y cada una de las casas de su señorío. Era la misma lógica por la que otras mujeres para manifestar los abusos que sufrían y a los que deseaban poner remedio ${ }^{27 a}$ acudían al alcalde del pueblo $o$ al corregidor 0 incluso a la autoridad judicial competente, en los territorios realengos.

26 DE las HerAS, J.L., La justicia penal de los austrias en la corona de Castilla, Salamanca, 1991. Alonso, M.P. El proceso penal en Castilla, siglo XI al xvm, Salamanca, 1982. Número monográfico Revista Studis dedicado al funcionamiento de la justicia, n. ${ }^{\circ}, 22,1996$.

A. D. V: Fondos Luna, leg. 2 bis, exp. 24. 1770.

27a ORTEGA, M., "Huertana de ciudadania pero guardianas de la casa" en Género y ciudadania, revisiones desde el ambito privado, UAM, Madrid, 1998. CLAVERO, B. Historia y antropologia, para una epistemologia del derecho moderno. Madrid, 1985. LASLETT, P., El mundo que hemos perdido, explorado de nuevo, Madrid, 1987. THOMPSON, E.P., Tradición, revuelta y conciencia de clase. Barcelona, 1979. ATIENZA, I., "Consenso, solidaridad vertical e integración versus violencia en los señorios castellanos", en Señorio y feudalismo en la península ibérica. Zaragoza, 1993, vol. II. 
Es perceptible en ocasiones una cierta desconfianza entre la justicia real y la señorial, aunque el canal de comunicación existente entre ambas, era ya lo suficientemente fluido durante el siglo XVIII. Existían diferencias notables ciertamente en cuanto a los procedimientos con los que operaban unos y otros ${ }^{28}$. Hecho, por lo demás, perfectamente constatable en la justicia europea, donde el derecho culto de las élites chocaba con las prácticas jurídicas de las sociedades campesinas, más basadas en costumbres de su cultura oral que en los procedimientos judiciales institucionales. No es sorprendente, por tanto, que, en ocasiones, la justicia real solicitase información a la de los regímenes señoriales sobre los procedimientos seguidos en determinadas causas. Se pedía, por ejemplo, el nombre de los abogados y procuradores que representaban a las personas encausadas o demandaban algún expediente pendiente para desarrollar algún juicio por la propia magistratura real pero también acerca de cómo se había investigado y recabado la información para solucionar las causas pendientes.

En la causa contra Domingo Arranz, vecino de un pueblo de Segovia, de jurisdicción señorial, la Chancillería de Valladolid obró expeditivamente solicitando con urgencia se le enviara a la sala de lo criminal el expediente por estupro de Arranz con una sobrina suya ${ }^{29}$. Habia información precisa sobre las tácticas de dilación y el poco interés que tenía la justicia del pueblo para resolver ese grave caso. La magistratura saldaba así las deficiencias de los tribunales menores a la par que salvaguardaba principios éticos fundamentales.

Desde un prisma individual, Clara Alvarez alegó desconfianza hacia los tribunales señoriales de su pueblo, en la provincia de Valladolid en 1751, y caminó ocho horas para solicitar justicia ante el alcalde de realengo más próximo a su localidad, en 1757. Las razones que alegó ${ }^{30}$ fueron que preveía que no iba a ser atendida su denuncia contra su marido, pues el alcalde era pariente de él y no "había de tomar en consideración su palabra". La actitud de esta mujer manifestaba su deseo de buscar y obtener protección judicial para impedir continuar soportando las vejaciones maritales y resalta la esperanza existente en el proceder de la magistratura.

El control que los tribunales reales ejercian en el siglo XVIII sobre todas las instancias intermedias de la sociedad corporativa del antiguo régimen,

\footnotetext{
28 Goody, J., The domestication of the savage, Cambridge, 1977. Santos, S., O discurso e o poder, ensaio sobre a sociologia da retórica jurídica, Coimbra, 1980.

29 A. CH. V. Pleitos Criminales, Caja 303-2. El alcalde tenía fama de vago y de retrasar mucho los expedientes pendientes; en 15 días se integró el pedido en la Chancilleria.

30 A. CH. V. Pleitos criminales, caja 163-2.
} 
permitía perfectamente tomar en consideración peticiones como las de Clara, que no eran excepcionales, conocido el amplio volumen de demandas judiciales desarrolladas durante el siglo XVIII a instancias señorial ${ }^{31}$.

\subsection{Otras acciones judiciales}

No siempre a través del pacto o de la recomendación a las partes era posible alcanzar la paz conyugal. En esos casos, las acciones judiciales se encaminaron por variados derroteros; pero el objetivo judicial seguía persiguiendo siempre mantener la unidad familiar, a pesar incluso de la existencia de malos tratos o de adulterio entre las partes. Los miembros de la magistratura intentaban convencer a los ofendidos y a las ofendidas a que perdonasen o pactasen e intentaran reanudar una convivencia lo más armoniosa posible. $Y$ para ello no se regateaban esfuerzos: se manipulaban situaciones personales, se coaccionaba o privaba de libertad, de modo transitorio, a alguna de las partes o incluso a ambas..., dejando sentado siempre el principio de la autoridad masculina y la necesaria obediencia de las mujeres hacia ella.

Ante cualquier denuncia grave, los jueces otorgaban el beneficio de la duda a los implicados, esperando que el arresto, que se desarrollaba a continuación, les sirviera de aviso frente a futuras acciones. Se pensaba que, en general, una corta estancia en prisión venía bien para subsanar comportamientos inadecuados y para que reflexionaran las partes en litigio y se pudiera lograr el acercamiento. A juzgar por la información existente en los archivos judiciales, este método fue bastante efectivo.

A Manuel Aguirre, un esposo de Villaro ${ }^{32}$, Vizcaya, le denunció su mujer en 1764 por adulterio y escándalo continuado. Se le introdujo en prisión dos años como medida cautelar, y antes de llegar a cumplir esa fecha, fue posible el acercamiento y el perdón de la esposa ofendida. Una carta del marido a la esposa, escrita a instancias de la magistratura con el ruego de perdón y su deseo de reanudar la convivencia conyugal, fue suficiente para que la esposa retirara su denuncia.

${ }^{31}$ Ortega, M., "Algunas formas de protesta antiseñorial en España durante la segunda mital del siglo XVIII, en Señorio y feudalismo en la peninsula ibérica. Zaragoza, 1993, Vol. II. Ibidem. Continuidad y conflicto en la sociedad española del siglo XVII. Madrid, 1993. CASTAN, N., Les criminals del Langedoc 1750-1790, Toulon, 1980. RuIz, P., Señores y propietarios, cambio social en el pais valenciano, 1650-1800. Valencia, 1981.

32 A. CH. V. Sala de Vizcaya, Leg. 1543-09. El concejo del pueblo apoyó la demanda de la esposa y se personó en la causa por escándalo, año 1746. 
Pero también existen testimonios de numerosas mujeres que habian acudido a los jueces en demanda de auxilio y cómo hubieron de aceptar reanudar la convivencia matrimonial, a pesar de haberse demostrado la extremada violencia conyugal con las que habian sido tratadas.

Ésa fue la resolución que tomaron los alcaldes del crimen de la chancillería de Valladolid, el 26 de agosto de 1749, en una causa por escándalo y malos tratos infringidos hacia una mujer de 31 años. El desencadenante parecía ser la convivencia en la casa del matrimonio de un hermano del marido, agricultor en Medina del Campo, y los celos del esposo originados por la supuesta relación afectiva entre los cuñados.

La sola denuncia que en sus alegaciones hacia el marido sobre el descuido de la administración doméstica de la esposa y cómo hacia una vida social "con personas que no eran de mi agrado" ${ }^{33}$, pareció ser definitiva para la pronta resolución de un caso que la Chancillería canalizó como causa reservada, por ser un asunto que competía a supuestas relaciones ilícitas entre cuñados, y que habían originado grave escándalo en la comunidad. La recomendación de la magistratura a la esposa fue conminarla a «hacer vida maridable, sin dar ocasión a disidencias, disensiones y desconfianza entre ellos, absteniéndose de tratar con personas que no fueran del agrado del marido".

$Y$ al esposo se le exigió que el hermano saliera de la casa, y que «trate con estimación, decoro y sin violencia alguna a la esposa, y muestre su autoridad sobre ella en todos sus actos".

A pesar de la súplica posterior de la mujer implicada, -que no deseaba volver al hogar familiar y que quería acudir a la casa paterna-, la decisión de la sala fue "que era obligada a hacer vida maridable". Ahí se termina el rastro documental de ese expediente; no resulta difícil - a la vista de los datos-suponer sus dificultades posteriores de convivencia, pero reanudar cualquier relación matrimonial era elemento central de los justiciables y todos sus actos se encaminaban a ello.

La mediación coaccionada con la que, a menudo, se prestaba la magistratura era abundante en el caso femenino. Manuel Berojo esposa de un labrador de Revilla Vallejera, Burgos, en 1781, fue conminada por la Chancillería de Valladolid a que perdonase a su esposo, un hombre violento cuyos malos tratos hacia ella se habían originado 15 años atrás y que decía estar arrepentido ${ }^{34}$. En casos de violencia, la reacción del esposo solía ser

33 A. CH. V. Causas secretas, leg. 6, exp. 4. Existía una gran alarma social en el pueblo por este caso, año 1749 .

34 A. CH. V. Escribania Pérez Alonso, leg. 3462-03, año 1781. 
demostrar que había intereses ocultos por parte de la mujer demandante. Para los magistrados, tampoco resultaban carentes de sospecha las peticiones de arresto de cualquier marido, pues pensaban que la violencia podía ser utilizada a modo de aviso y escarmiento, y no deseaban que el arresto del esposo generase una ruptura de la convivencia familiar. En este caso, Manuela hubo de aceptar una convivencia que no deseaba, pero a la que no podía sustraerse. No obstante siempre era más fácil al esposo obtener credibilidad ante los tribunales de justicia a que la esposa y especialmente en aquellos casos concernientes a temas referentes al honor.

Por ejemplo, Manuel Mansilla, vinatero de Vicalvaro, logró en 1777 que su mujer Isabel Alonso fuese encerrada tres años en el hospicio de San Fernando de Madrid por "desobediencia contumaz a mi autoridad" ${ }^{35}$, y ésa era la razón por la que estaban en el último tercio del siglo XVII la mayoria de las mujeres privadas de libertad en el hospicio de San Fernando de Madrid ${ }^{36}$.

En cambio, a Josefa Ceballos, esposa de un coronel militar del Puerto de Santa María, le resultó casi imposible demostrar el adulterio y los malos tratos padecidos desde $1731^{37}$. Sus expectativas se vieron incumplidas y mucho menos logró el arresto del esposo que perseguía. A instancias conjuntas del marido y del juez-vicario de Sevilla se la internó en un convento del propio Puerto de Santa María y para paliar ese hecho y según la resolución judicial, el esposo habia de pagar los 400 ducados anuales que costaba el hospedaje en el convento; pues «aunque en uso de la potestad que el derecho divino concede a los maridos, pudiera mi persona corregir con alguna aspereza a mi mujer (...) juzgo ser mi parte más acertada y prudente acudir al recogimiento de mi señora".

En efecto, recoger a las mujeres que no obedecian a la autoridad marital fue una solución muy utilizada en la sociedad del antiguo régimen. Se perseguía corregir de este modo su rebeldía, a la vez que se mostraba su inconveniencia de conducta y el deseo de encauzarlas convenientemente. La magistratura cuando había peticiones de un cabeza de familia agraviado, no dudaba en darle pronta solución de éste o de otro modo. Estas soluciones fueron muy utilizadas.

35 A. H. N. Consejos, libro 1365, folios 445-46. Se la tachaba de malentretenida y conducta sospechosa.

36 Correcher, I., La revuelta del cuartel de mujeres del hospicio de San Fernando de 1786. Madrid, 1998.

37 A. H. N. Estado, Leg. 4828. La esposa decia llevar «una intolerable y mala vida con él junto a malos tratos continuados". 
Conventos, colegios, hospicios, cárceles o incluso casas de depósito casas de particulares que acogían a mujeres en estos trances-, eran formas de habitación habitual para estas mujeres con problemas. En algunos casos, las propias mujeres acudian voluntariamente a esos lugares para zafarse de situaciones calamitosas pero, en la mayoría de los casos, solía ser como consecuencia de la imposición marital. La frecuencia de esas situaciones fue importante, aunque poco conocemos de las condiciones de su aislamiento. Con todo alguna noticia de esas situaciones es posible rescatar: María Nicolasa Sáez, encerrada a instancias de su marido en un convento en Ávila, solicitaba en 1790 poder ver a sus tres hijos: "de los que se me ha separado vilmente, sin haber cometido más causa que desaprobar la vida corrompida de mi marido" ${ }^{38}$. Evidentemente de ésta y otras historias es fácil deducir la utilidad que estos lugares de depósito tenía para maridos astutos que querian zafarse de la convivencia de la esposa con la complacencia plena de la justicia ${ }^{39}$.

La política de vasos comunicantes entre la autoridad judicial y el cabeza de familia agraviado era palmaria: a una esposa a la que se le recriminó por desobediencia marital en 1781 y que se la encerró en el hospicio de San Fernando, la sala de alcaldes de casa y corte del Consejo de Castilla la apercibía de este modo: "el marido es el primero en el matrimonio, y ha de tener el principado, señorio y gobernación de la esposa y ella, como cosa suya, ha de estar sujeta y obedecerlem ${ }^{40}$. Y ese discurso univoco hacia la autoridad masculina era el que moralistas, confesores y ensayistas de todo tipo conjugaban constantemente. Obviamente esa unidad de criterios en discurso oficial salió muy fortalecido. Los comportamientos de otras sociedades afines como la sociedad colonial, en materia matrimonial, discurrian por cauces muy similares ${ }^{41}$. Tanto en el territorio español como en el colonial la adecuada manutención y decoro de la mujer encerrada por mandato judicial, corria a cargo del cabeza de familia, por lo que no era infrecuente que se presionase y negociase extensamente las condiciones económicas del encierro de la esposa, resultando ser ésta una sutil presión más para que aquéllas aceptaran la obediencia del "pater familias».

A pesar del enojo de una esposa de un caballero de Valencia, por la precariedad económica de su pensión asignada en el convento de Santa

38 A. H. N. Estado, leg. 4828, año 1790. Decía que no gustaba de la vida “libertina y relajada que llevaba su esposa, pues era madre cristiana y mujer virtuosa".

39 PITA, T., Mujer, conflictos y vida cotidiana en el Méjico borbónico. Alcalá de Henares, 1999. ORTEGA, M., "Género y relaciones familiares...".

40 Rodriguez Lusitano, M., Suma de casos de conciencia. Salamanca, 1604. Arbiol, F. La familia regulada, Zaragoza, 1714. HeRRERA, A., Espejo de la perfecta casada. Madrid, 1667.

41 PITA, T., Mujer conflictos... Gonzalvo, P. (Ed.), Familias novohispanas, siglos XVI al XIX. Méjico, 1991. 
Clara de su ciudad, el marido hizo imponer su autoridad en su negociación y su aislamiento del exterior ${ }^{42}$.

No obstante, el depósito de la esposa fuera del hogar conyugal resultaba ser un hecho incómodo y sospechoso para el cabeza de familia implicado. Demostraba incapacidad o dificultades para ejercer la potestad sobre la familia, y además gastos económicos evidentes; en suma, desprestigio social para ese "pater familias" poco cuestionado en su poder. Indudablemente la estrategia del esposo y el "status" social de la familia de la esposa, condicionaba la resolución de los tribunales sobre determinados asuntos matrimoniales.

La molesta esposa de un noble granadino, no accedió en 1751, a las presiones y mandatos con las que el esposo la coacionaba, y que no era sino acceder a llevar una vida más conforme con la moda «liberal del cortejo". Solicitó la mediación de su confesor e ingresó en un convento de la ciudad, exigiendo «una pensión alimenticia conforme a mi rango y condición" "43. Estaba más a gusto en la paz conventual que en el hogar conyugal. El esposo no puso reparos por la cuantía de la pensión que había de otorgarla. Al parecer ambos no tenían interés alguno en retomar la convivencia de la pareja.

Incluso es posible detectar cómo los tribunales solicitaban a menudo sugerencias del cabeza de familia a la hora de infringir las penas de privación de libertad para las esposas rebeldes.

La mayor o menor duración del encierro, quedaba predeterminada por la aceptación o desaprobación efectuada por el marido pertinente. Pero existian también casos particulares en los que el esposo agraviado, quizás conmovido por la trascendencia de su denuncia, solicitaba al tribunal la suspensión del encierro - que el mismo había propiciado-, a la par que se responsabilizaba de nuevo del tutelaje de la esposa ${ }^{44}$.

Esa era la razón que aducía un marido de Leganés, y se desdecía de su deseo inicial de recluir a la esposa un año en el hospicio de San Fernando. Argumentaba razones de humanidad y la reforma de conducta de la esposa encerrada, que prometía obediencia y afabilidad hacia él ${ }^{45}$.

42 A. H. N. Estado, leg. 4828. La esposa alegaba extremada incomunicación con el exterior e imposibilidad de ver a sus dos hijos de corta edad.

${ }_{43}$ A. H. N. Estado, Leg. 4848. El esposo la trataba de ubeata dominada por el confesor".

44 Ortega, M., "La defensa de las mujeres....". CorReCher, I., La revuelta del cuartel..

45 A. H. N. Consejos, libro 1371. Un marido de Leganés, ventero de profesión, solicitaba en 1783 a la Sala de Alcaldes la salida de su esposa del hospicio pues clos cuatro meses de recoleción la han permitido reformarse y aceptar mi autoridad". 
La interrelación profunda entre los magistrados y los maridos con mujeres rebeldes, se mostraba igualmente en la pronta aceptación que la magistratura observaba hacia esas peticiones. Tampoco era menor la complicidad de los tribunales eclesiásticos con los maridos. Entendian también que la cárcel o el enclaustramiento era un lugar transitorio para retractar conductas desviadas y por eso no dudaron los jueces eclesiásticos en acceder a peticiones fundamentadas de algunas maridos agraviados.

El tribunal eclesiástico de Ibiza, por ejemplo, que compartía con la jurisdicción real el análisis de las causas matrimoniales de la isla, accedió a la petición del marido de sacar a su esposa, de 27 años, de una casa de acogida, en 1747, para sancionar su conducta escandalosa. Esa no habia sido sino "salir sola por la calle, asomarse al balcón y pretextar demasiados recados a resolver fuera de la casa" - según la testificación del esposo- ${ }^{46}$. Al parecer la mujer había prometido retractarse de conducta tan libre y aceptar la vida doméstica y recluida que el esposo la demandaba.

46 Archivo Diocesano de Ibiza (A.D.I.). Causas matrimoniales, leg. 10, exp. 15. en DemERSoN, J.P., Sexo, amor y matrimonio en Ibiza en la época de Carlos III. Palma de Mallorca, 1993. 